\title{
Bone marrow-derived cells can acquire renal stem cells properties and ameliorate ischemia-reperfusion induced acute renal injury
}

\author{
Xiaohua Jia ${ }^{1,2 \dagger}$, Xiaoqiang Xie ${ }^{3 \dagger}$, Guowei Feng $^{3}$, He Lü ${ }^{4}$, Qinjun Zhao ${ }^{5}$, Yongzhe Che $^{2}$, Yizhou Zheng ${ }^{5}$, \\ Zhongchao $\mathrm{Han}^{5}$, Yong $\mathrm{Xu}^{3^{*}}$, Zongjin $\mathrm{Li}^{1,2^{*}}$ and Deling Kong ${ }^{1}$
}

\begin{abstract}
Background: Bone marrow (BM) stem cells have been reported to contribute to tissue repair after kidney injury model. However, there is no direct evidence so far that BM cells can trans-differentiate into renal stem cells.

Methods: To investigate whether BM stem cells contribute to repopulate the renal stem cell pool, we transplanted BM cells from transgenic mice, expressing enhanced green fluorescent protein (EGFP) into wild-type irradiated recipients. Following hematological reconstitution and ischemia-reperfusion (I/R), Sca-1 and c-Kit positive renal stem cells in kidney were evaluated by immunostaining and flow cytometry analysis. Moreover, granulocyte colony stimulating factor (G-CSF) was administrated to further explore if G-CSF can mobilize BM cells and enhance transdifferentiation efficiency of BM cells into renal stem cells.

Results: BM-derived cells can contribute to the $\mathrm{Sca}^{-1}{ }^{+}$or $\mathrm{C}-\mathrm{Kit}^{+}$renal progenitor cells population, although most renal stem cells came from indigenous cells. Furthermore, G-CSF administration nearly doubled the frequency of Sca-1+ BM-derived renal stem cells and increased capillary density of I/R injured kidneys.
\end{abstract}

Conclusions: These findings indicate that BM derived stem cells can give rise to cells that share properties of renal resident stem cell. Moreover, G-CSF mobilization can enhance this effect.

Keywords: Bone marrow transplantation, Trans-differentiation, Renal stem cell, Acute kidney injury, G-CSF, Mobilization

\section{Background}

Chronic kidney disease (CKD) and end-stage renal disease (ESRD) are associated with considerable morbidity and mortality. Current treatments fail to cure CKD and can't halt progression of CKD to ESRD [1]. Despite advances in the understanding of glomerular and tubular injury and regeneration, therapeutic advances have been limited because of the organ shortage for renal transplantation and the complexity of kidney. Stem cell-based therapy is a new strategy in the treatment of acute kidney injury and has

\footnotetext{
*Correspondence: xuyong8816@sina.com; zongjinli@nankai.edu.cn ${ }^{\dagger}$ Equal contributors

'State Key Laboratory of Medicinal Chemical Biology, Key Laboratory of Bioactive Materials, Ministry of Education, Nankai University, Tianjin 300071, China

${ }^{3}$ Department of Urology, Second Hospital of Tianjin Medical University, Tianjin Institute of Urology, Tianjin 300211, China

Full list of author information is available at the end of the article
}

potentially more value than single-agent drug therapy due to the highly versatile response of cells to their environment [2]. The potential cellular sources for kidney regeneration include renal resident stem cells and extra-renal stem cells. A number of recent studies have confirmed the presence of cells bearing stem cell markers such as Sca-1, c-Kit, and CD133 in the kidney [3-10]. These cells can differentiate, proliferate, and eventually reline denuded tubules, restoring the structural and functional integrity of the kidney. However, the homeostasis of renal stem cells in kidney is still under investigation.

Differentiation of bone marrow (BM) derived-cells into cells of non-haematopoietic origin has been described in several in vivo studies and gave rise to the thought that the BM-derived cells population could be involved in tissue turnover and regeneration, including kidney [2,11-13]. It has been hypothesized that the stem cell repertoire of

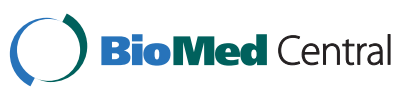

(C) 2012 Jia et al.; licensee BioMed Central Ltd. This is an Open Access article distributed under the terms of the Creative Commons Attribution License (http://creativecommons.org/licenses/by/2.0), which permits unrestricted use, distribution, and reproduction in any medium, provided the original work is properly cited. 
adult tissues generally consists of a small number of selfreplenishing cells that differentiate from primate bone marrow cells [14]. The movement of stem cells is critical for homeostasis and repair in adulthood.

Identification of stem cells in kidney tissues is important for therapeutic applications and for understanding developmental processes and tissue homeostasis. Previous research revealed that the BM-derived hematopoietic stem cells (HSCs) can reside in kidney and differentiate into mature cells [15]. Furthermore, the turning over of BM derived stem cells into renal stem cells has not been investigated so far. In this study, we sought to address the plasticity of BM stem cells in trans-differentiating into renal stem cells and BM derived stem cells in kidney regeneration after acute kidney injury (AKI), as well as the fortified effects of granulocyte colony-stimulating factor (G-CSF) in mobilizing bone marrow stem cells trans-differentiate into renal stem cells.

\section{Methods}

Isolation and transplantation of bone marrow cells

Animal protocols were approved by the Nankai University Animal Care and Use Committee. Mice were anesthetized with inhaled isoflurane (2\% to $3 \%) .8$ to 10 week-old female C57BL/6 J mice (The Laboratory Animal Center of The Academy of Military Medical Sciences, Beijing, China) ( $\mathrm{n}=30$ per group) were irradiated with 9.5 Gy of $\gamma$-irradiation in 2 divided doses, 2 hours apart, on the day of surgery. Bone marrow cells were isolated from the femur and tibia of 8 to 10-week-old female C57BL/6 J-TgN mice (The Laboratory Animal Center of The Academy of Military Medical Sciences, Beijing, China), transgenically expressing the chicken $\beta$-actinEGFP gene, by flushing with Iscove's minimal essential medium (IMEM). For bone marrow transplantation (BMT), wild-type irradiated mice were injected with $0.2 \mathrm{ml}$ PBS with or without $2.0 \times 10^{5} \mathrm{BM}$ mononuclear cells via tail veins at 2 hours after irradiation. Mice were kept in a specific pathogen free facility and drinking water containing enrofloxacin $(0.15 \mathrm{mg} / \mathrm{ml})$ and amoxicillin $(1 \mathrm{mg} / \mathrm{ml})$ were given for 4 weeks to prevent infection.

\section{Acute kidney ischemia/reperfusion experiments}

Acute left kidney ischemia/reperfusion was carried out at 5-week after BMT. Mice were anesthetized by intraperitoneal injection with $300 \mathrm{mg} / \mathrm{kg}$ chloraldurat. Animals were placed on a heating pad to maintain a constant temperature and monitored with a rectal thermometer. A midline abdominal incision was made, and left kidneys were exposed. The left renal artery was separated from the vein and clamped for $30 \mathrm{~min}$ followed by clamp release to allow reperfusion. Throughout ischemic period, evidence of clamping was confirmed by visualizing dark color of ischemic kidneys. After clamp removal, adequate restoration of blood flow was checked before abdominal closure. Sham-operated animals underwent anesthesia, laparotomy, and renal pedicle dissection only.

\section{Mobilization of bone marrow stem cells following ischemic injury}

For HSCs mobilization, mice received a subcutaneous injection of $200 \mu \mathrm{g} / \mathrm{kg}$ recombinant G-CSF daily for 8 days from 5 before induction of ischemia. Control mice received an injection of saline ( $\mathrm{n}=15$ per group).

\section{Flow cytometry analysis}

To measure stem cells mobilization, flow cytometry analyses (FACScan flow cytometer, Becton Dickinson) were performed on day 9 and 33 after administration of G-CSF. The peripheral blood was stained with Alexa Fluor ${ }^{\circledR}$ 647conjugated rat anti-mouse CD34, APC-labeled anti-mouse c-Kit and CD45, and PE-labeled rat anti-mouse Sca-1, Flk1 and rat anti-mouse CD29, (all from BD Pharmingen). 5 weeks after BMT, bone marrow engraftment efficiency in recipients was determined by analyzing GFP expression of peripheral blood.

\section{Isolation and characterization of renal progenitor cells after BMT}

Nine weeks after BMT, the intact kidney tissue was minced and added to $10 \mathrm{ml}$ of a $4 \mathrm{mg} / \mathrm{ml}$ solution of dispase (sigma-Aldrich) in DMEM (Invitrogen). The minced tissue and media were transferred to a 50-ml Erlenmeyer flask and incubated for $1 \mathrm{~h}$ at $37^{\circ} \mathrm{C}$. Following the incubation, the tissue was filtered through $40 \mu \mathrm{m}$ nylon cell strainer (BD Pharmingen) to remove cell segments [7]. Kidney cell suspensions were washed twice in DMEM and stained with Sca-1, c-Kit, Flk-1, CD29, CD34 and CD45 for FACS analysis.

\section{Histology and immunohistochemistry}

Four, 8 and 48 weeks after I/R, mice were euthanized and the kidneys were thoroughly perfused with saline to remove blood from the vascular beds. The specimens of kidney were embedded into paraffin or OCT compound (Miles Scientific), then sectioned to $5 \mu \mathrm{m}$ slides and processed for hematoxylin-eosin, Masson staining and immunostaining. To track BM-derived cells in kidneys, rabbit anti-c-Kit antibody (Santa Cruz), mouse monoclonal smooth muscle actin ( $\alpha$-SMA, Boster Co., China), monoclonal anti-mouse Sca-1 (Cedarlane), and rat anti-mouse CD45, CD29, CD105 (all from BD Pharmingen) were used. Alexa Fluor 594 and Alexa Fluor 488-conjugated secondary antibodies (Invitrogen) were applied appropriately. DAPI was used for nuclear counterstaining. To detect vascular density in the infarct area, a rat anti-mouse CD31 antibody was used. For immunohistochemistry, the endogenous peroxides were 
blocked using $3 \% \mathrm{H}_{2} \mathrm{O}_{2}$ in $\mathrm{PBS}$ at room temperature for 10 minutes. After being blocked with $10 \%$ goat serum in PBS, the sections were stained with primary antibody (mouse monoclonal anti-GFP, Abcam 1:500) overnight at $4^{\circ} \mathrm{C}$, biotinylated secondary antibody for 45 minutes at $37^{\circ} \mathrm{C}$, and diaminobenzidine reagent (Vector Laboratories) for 4 minutes. The numbers of BM-derived renal stem cells and capillary vessels were counted by a blinded investigator (LH) in 10 randomly selected high-power fields (HPF) using a fluorescence microscope $(\times 400)$ [12]. The blood vessel density was expressed as capillaries/HPF $(\times 400)$. The numbers of $\mathrm{BM}$-derived renal stem cells were counted as $\mathrm{GFP}^{+} \mathrm{Sca}-$ $1^{+}$cells/HPF and $\mathrm{GFP}^{+} \mathrm{c}-\mathrm{Kit}^{+}$cells/HPF $(\times 400)$.

\section{Statistical analysis}

All data are expressed as mean values \pm SEM. One-way analysis of variance was employed for comparing differences between groups. Least significant difference (equal variances) and Dunnett's T3 (non-equal variances) post hoc tests were used for testing the differences between groups. All tests were two-tailed, and significance was accepted at $P<0.05$.

\section{Results}

Hematopoietic reconstruction and engraftment of GFP positive cells into damaged kidney

Five weeks after BMT, hematopoietic reconstruction of recipient mice were confirmed by robust expression of GFP $(83.0 \pm 4.2 \%)$ and CD45 $(93.4 \pm 5.2 \%)$ in peripheral blood by FACS analysis (Figure 1A). Four weeks after I/R injury, kidneys were harvested and the engraftment of $\mathrm{BM}$-derived $\mathrm{GFP}^{+}$cells into damaged kidneys was evaluated by histology. There were widespread $\mathrm{GFP}^{+}$cells infiltrated in the injured kidney of saline-treated group, implicating the migration and engraftment of BM derived stem cells into kidneys. What is intriguing, much more $\mathrm{GFP}^{+}$cells were observed in the G-CSF administered mice compared to the saline-treated ones. But no $\mathrm{GFP}^{+}$cells were detected in the damaged kidney of wild type (WT) mice (Figure 1B). Furthermore, GFP expression in kidney from chimeric mice that underwent $\mathrm{I} / \mathrm{R}$

A
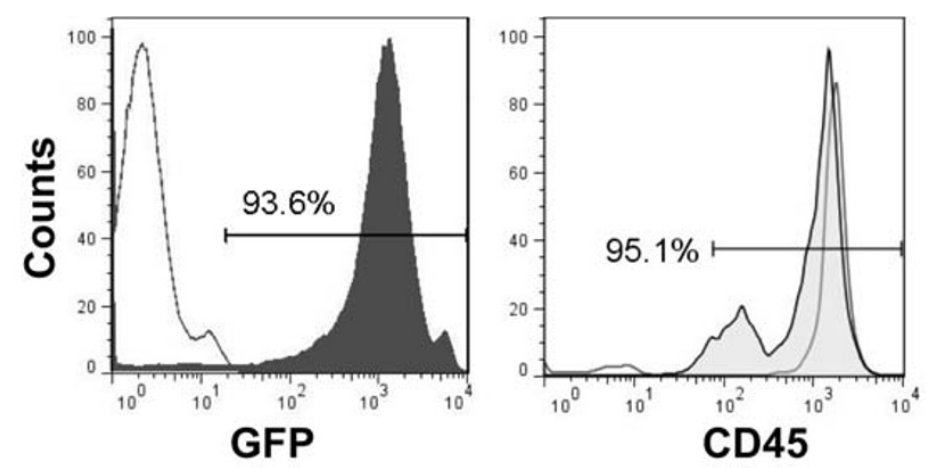

B

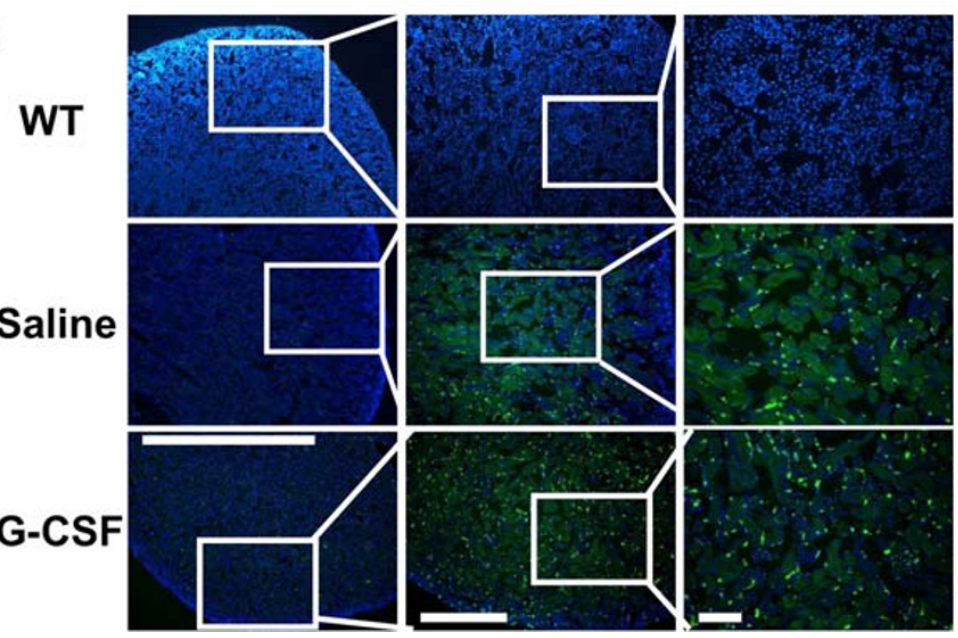

Figure 1 Engraftment of BM derived cells into I/R-injured kidneys. (A) Confirmation of chimerism in mice transplanted with bone marrow from GFP mice. Representative peripheral blood from wild-type (WT) mice and chimeric BMT mice 5 weeks after BMT were analysised by FACS. CD45 expression in recipient mice was also evaluated at the same time point. (B) BM-derived GFP positive cells within recipient kidneys. No GFP ${ }^{+}$ cell was observed in WT mice, while donor derived $\mathrm{GFP}^{+}$cells were widely infiltrated in saline-treated mice. G-CSF administration mobilized more BM-derived cells to the injured kidney compared to the saline-treated mice. Nuclei were stained with DAPI (blue). Scale bars $=50 \mu \mathrm{m}$. 
injury was confirmed by immunohistochemical staining. Additional file 1: Figure S1 showed that $\mathrm{GFP}^{+}$cells localized in the glomeruli and interstitium in consecutive sections of the injured kidney from the mice sacrificed 6 months after ischemic injury.

\section{Bone marrow-derived cells can acquire renal stem cells properties}

BM derived stem cells differentiation and acquisition of renal fate involved the engraftment of the donor cells within the host kidney. 4 weeks after injury, transplanted BM derived stem cells were seeded within renal tubules and were integrated structurally with resident cells. However, most BM derived stem cells were CD45-negative (data not shown). The presence of GFP was used to distinguish resident from injected CD45-positive cells. Immunostaining demonstrated that BM-derived cells contributed to the $\mathrm{Sca}-1^{+}$or $\mathrm{c}-\mathrm{Kit}^{+}$renal stem cells, although most renal stem cells came from indigenous cells (Figure 2A). Some Sca- ${ }^{+}$or $\mathrm{c}-\mathrm{Kit}^{+}$cells were detected in the engrafted $\mathrm{BM}$ derived stem cells (Figure 2A), and more $\mathrm{Sca}-1^{+} / \mathrm{GFP}^{+}$or $\mathrm{c}-\mathrm{Kit}^{+} / \mathrm{GFP}^{+}$renal stem cells in the ischemic kidneys (Figure 2B-C), which suggesting that the renal microenvironment may change the fate of $\mathrm{BM}$ derived stem cells, and BM derived stem cells home to the kidney where they lose the hematopoietic phenotype and acquire renal stem cells lineage.
G-CSF can mobilize BM-derived stem cells and enhance differentiation of BM cells into renal stem cells

To determine whether G-CSF induced stem cells mobilization would affect renal recovery, FACS and immunohistology analysis were carried out. Analysis of peripheral blood revealed that one day after last injection of G-CSF, all of the stem cell markers were increased in peripheral blood mobilized with G-CSF as compared with control group (Figure 3). There was a kind of respectively more than 2 -fold increase in the total number of $\mathrm{CD}_{3} 4^{+}, \mathrm{Sca}-1^{+}$or $\mathrm{c}-\mathrm{Kit}^{+}$cells in cytokine-treated animals compared with controls. However, G-CSF treatment did not lead to significantly increased numbers of circulating $\mathrm{CD} 45^{+}$cells compared with controls $(91.1 \pm 5.3 \%$ versus $96.8 \pm 6.5 \%, P>0.05)$.

Furthermore, 4 weeks after I/R injury, the flow cytometry examination of kidney cells revealed the number of BM-derived $\mathrm{GFP}^{+}$cells and the apparent populations of stem cells in the adult kidneys. G-CSF promoted more stem cell engraftment in damaged kidneys comparing with saline treated (Figure 4). Notably, G-CSF treatment nearly doubled the frequency of Sca-1 expressing BM-derived $\mathrm{GFP}^{+}$cells $(2.1 \pm 0.6 \%$ versus $0.9 \pm 0.5 \%)$. Similarly, G-CSF statistically increased the Sca- $1^{+} / \mathrm{GFP}^{+}$cells, through immunofluorescence staining compared with Saline group ( 4 w $7.5 \pm 1.3$ cells/ $\mathrm{HPF}$ versus $3.5 \pm 0.6$ cells $/ \mathrm{HPF}$, and $8 \mathrm{w} 9.4 \pm 1.4$ cells/
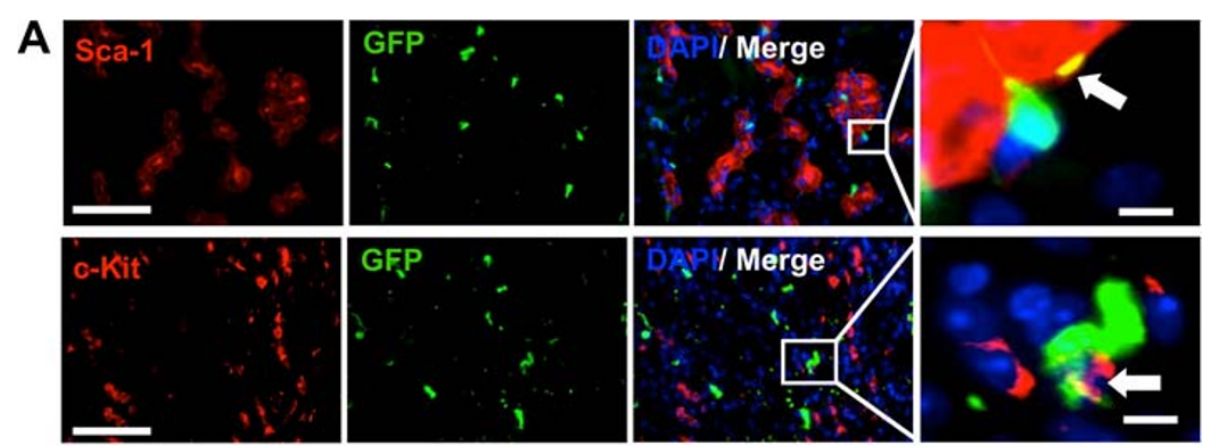

B

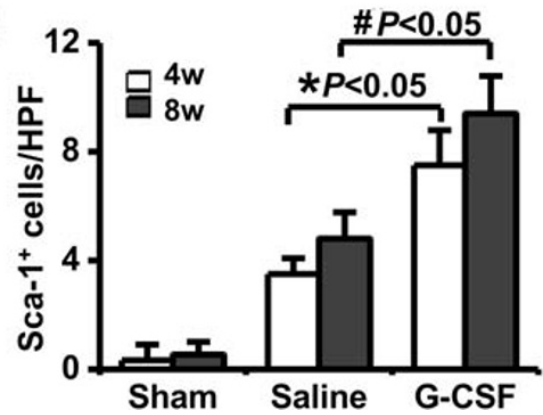

C

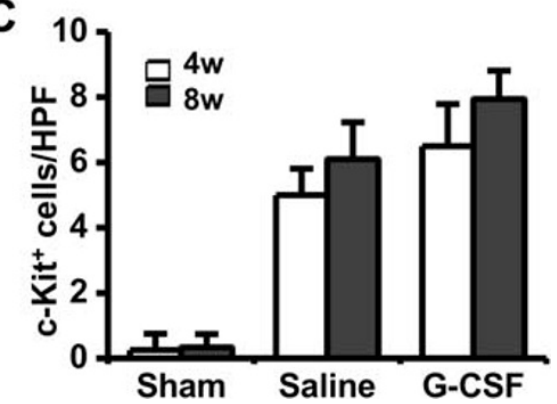

Figure 2 BM derived stem cells can acquire renal stem cells characteristics. (A) Renal stem cells positive for GFP and Sca-1 or c-Kit were showed in merge (arrowhead). Nuclei were stained with DAPI (blue). Scale bars $=50 \mu \mathrm{m}$ (left) and $5 \mu \mathrm{m}$ (right), respectively. (B) Quantitative analysis of renal stem cells revealed that G-CSF administration nearly doubled the frequency of Sca-1 expressing BM-derived renal stem cells. ${ }^{*} P<0.05$ vs. 4 w Saline group; ${ }^{\#} P<0.05$ vs. 8 w Saline group. (C) Quantitative analysis of c-Kit positive renal progenitor cells. HPF: high-power field, (×400). 


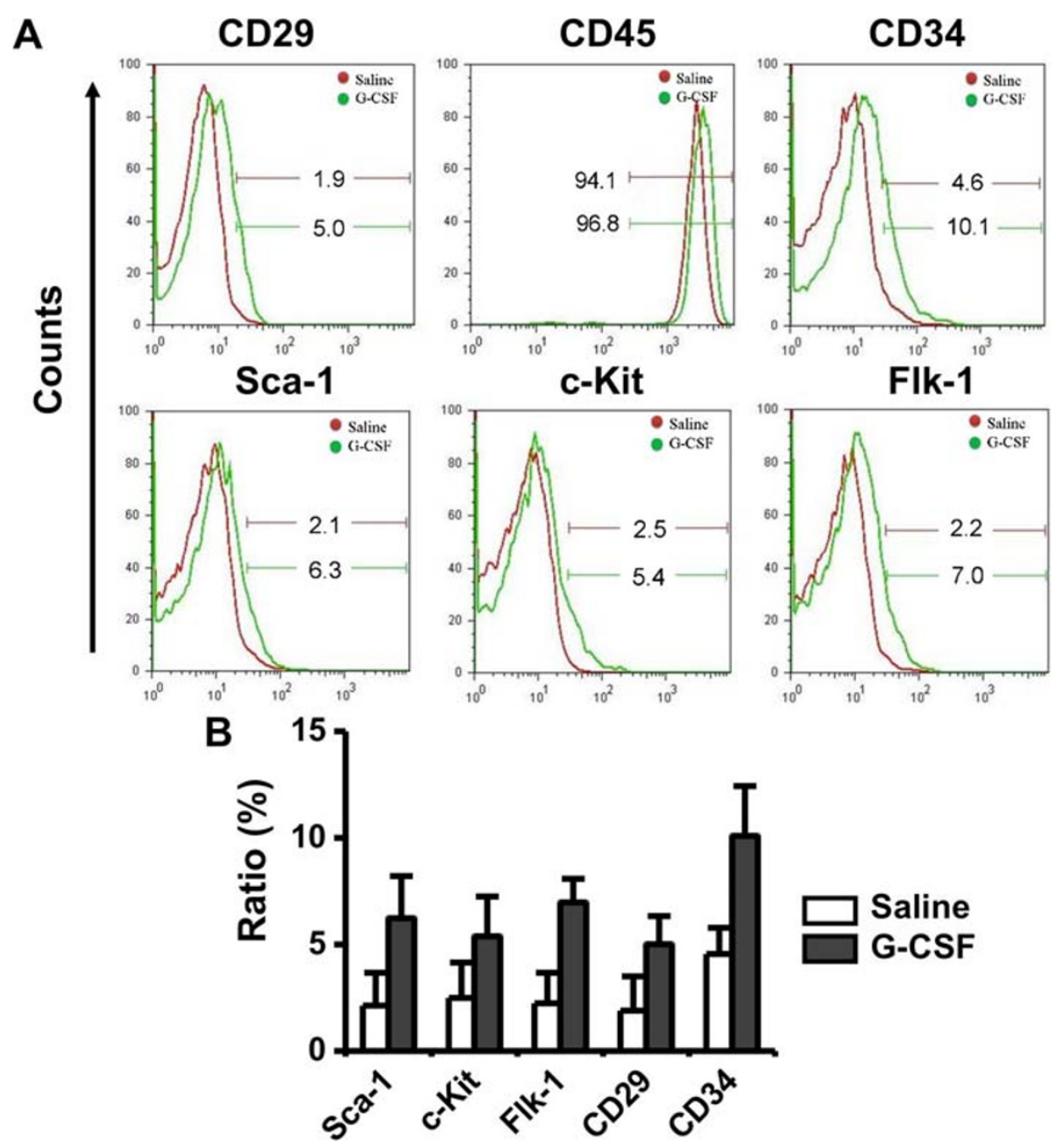

Figure 3 G-CSF increased the mobilization of BM stem cells into peripheral blood. (A) FACS analysis of peripheral blood, saline (red line) or G-CSF (green line). (B) Quantitative analysis of cell markers examined by FACS. Comparing with saline group, G-CSF group expressed higher stem cell markers such as Sca-1, c-Kit, Flk-1, CD29 and CD34.

HPF versus $4.8 \pm 1.0$ cells/HPF, $P<0.05$, Figure $2 \mathrm{~B}$ ). Although G-CSF also promoted $\mathrm{GFP}^{+} \mathrm{BM}$ stem cells differentiation into c-Kit ${ }^{+}$renal stem cells, the increased extent was lower than Sca-1 ${ }^{+} \mathrm{GFP}^{+}$cells. (Figures 2 B-C, 4).

\section{BM-derived stem cells mediated protective effects for renal ischemia-injury}

To study the profitably angiogenic and/or vasculogenic effects of BM-derived stem cells at week 4 after ischemia, the renal sections were examined by immunofluorescence. CD105, one marker of endothelial cells, was found to be co-expressed in some subset of $\mathrm{GFP}^{+}$cells (Figure 5A). Sections were also stained with smooth muscle marker $\alpha$ SMA, a part of GFP co-expressing cells showed good match with $\alpha$-SMA-positive cells in post-ischemic kidneys (Figure 5B). Besides, as shown in Figure 5C, anti-CD31 staining revealed higher microvessels density (MVD) in the G-CSF treated group comparing to the control group
(31.4 \pm 4.9 capillaries/HPF versus $20.5 \pm 3.1$ capillaries/ HPF, $P<0.05$, Figure 5C, D). We have also assessed the histological changes in kidney by H\&E staining of shamoperated, saline-treated, and G-CSF-treated groups in short and long term following I/R injury (Figure 6). At day 3 , there was extensive tubular swelling, necrosis in salinetreated group. In contrast, kidneys from G-CSF treated group showed slight tubular swelling after acute injury, but no renal damage was observed in sham-operated group. By day 28, necrotic injury almost disappeared and regenerating cells were observed to cover the tubules in both saline- and G-CSF-treated groups.

\section{Discussion}

Although therapeutic administration in animal models of acute renal injury suggested that BM stem cells based therapy may improve the recovery of both glomerular and tubular compartments, the suitability of these cell 


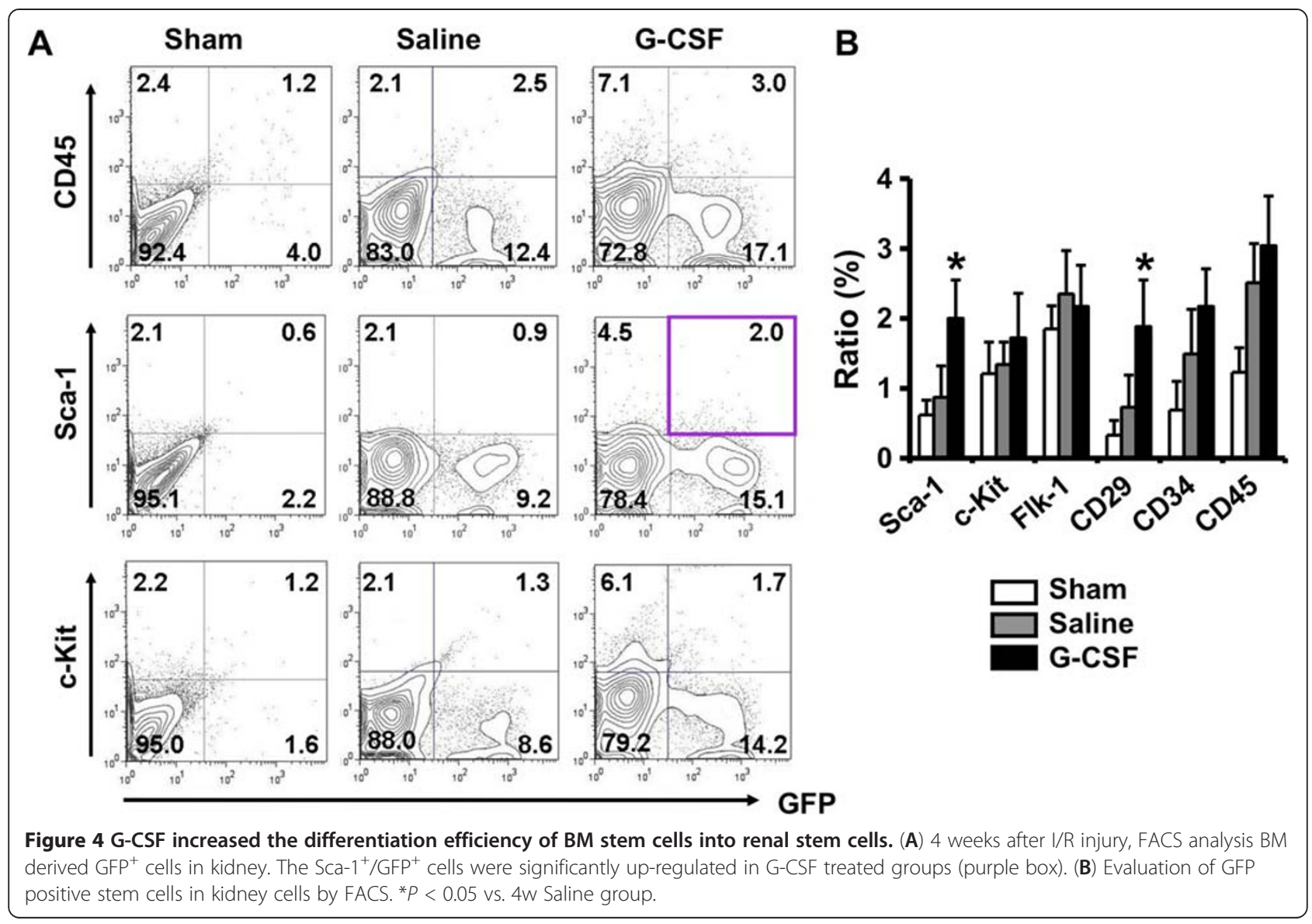

tenants for their new home in kidney has not been well investigated so far. In this study, our results indicate that transplanted BM derived stem cells can engraft, survive in kidney with ischemia injury, and acquire the renal stem cells phenotypes restoring renal ischemia injury. Our studies revealed here for the first time that BM derived stem cells could differentiate into renal stem cells and integrate with host renal cells. Furthermore, this process can be enhanced by G-CSF administration.

Recent works have documented the presence of a reservoir of stem and progenitor cells in the interstitium, papilla, urinary pole of kidney and these cells have been successfully isolated and expanded ex vivo [3-10]. The surface markers, such as CD133, CD24, PAX-2, c-Kit and Sca-1, were exploited to define putative renal stem/ progenitor cells in kidney [5,6]. These cells, lacked hematopoietic markers, demonstrated self-renewal under culture conditions, and differentiated into epithelial and endothelial cell types in vitro and incorporated into tubules following glycerol induced tubular necrosis in vivo $[6,8]$. Several works using renal stem cells also have demonstrated significant improvement in renal function after renal progenitor cells injection $[4,16,17]$. However, they more focus on the identification of stem cells, and reckon without the isolation efficacy of this kind of cells. The demand for renal stem cells is increasing for end-stage renal disease (ESRD) due to severe shortage of donor organs. Furthermore, as end stage of CKD, kidneys of ESRD are already small and fibrotic, endogenous renal stem cells have exhausted and other origins should be investigated.

The bone marrow constitutes the main reservoir of stem cells, and these cells can egress from the marrow niches, enter the systemic circulation [14]. The role of $\mathrm{BM}$ derived stem cells in repair or rejuvenation of tissues and organs that undergo injuries or degeneration has been drawn increasing attention. It was previously proposed that bone marrow derived cells could differentiate into renal cells and contribute to kidney regeneration following renal ischemia/reperfusion injury $[15,18]$. However, subsequent studies have demonstrated that only a few bone marrow derived cells engraft injured tubules and that their overall contribution to renal repair was negligible [19-21]. Recent results showed that bone marrow derived cells could migrate to damaged kidneys and participate in functional and structural recovery [2224]. Furthermore, several studies demonstrated that the infusion of human or mice derived MSCs contribute to 


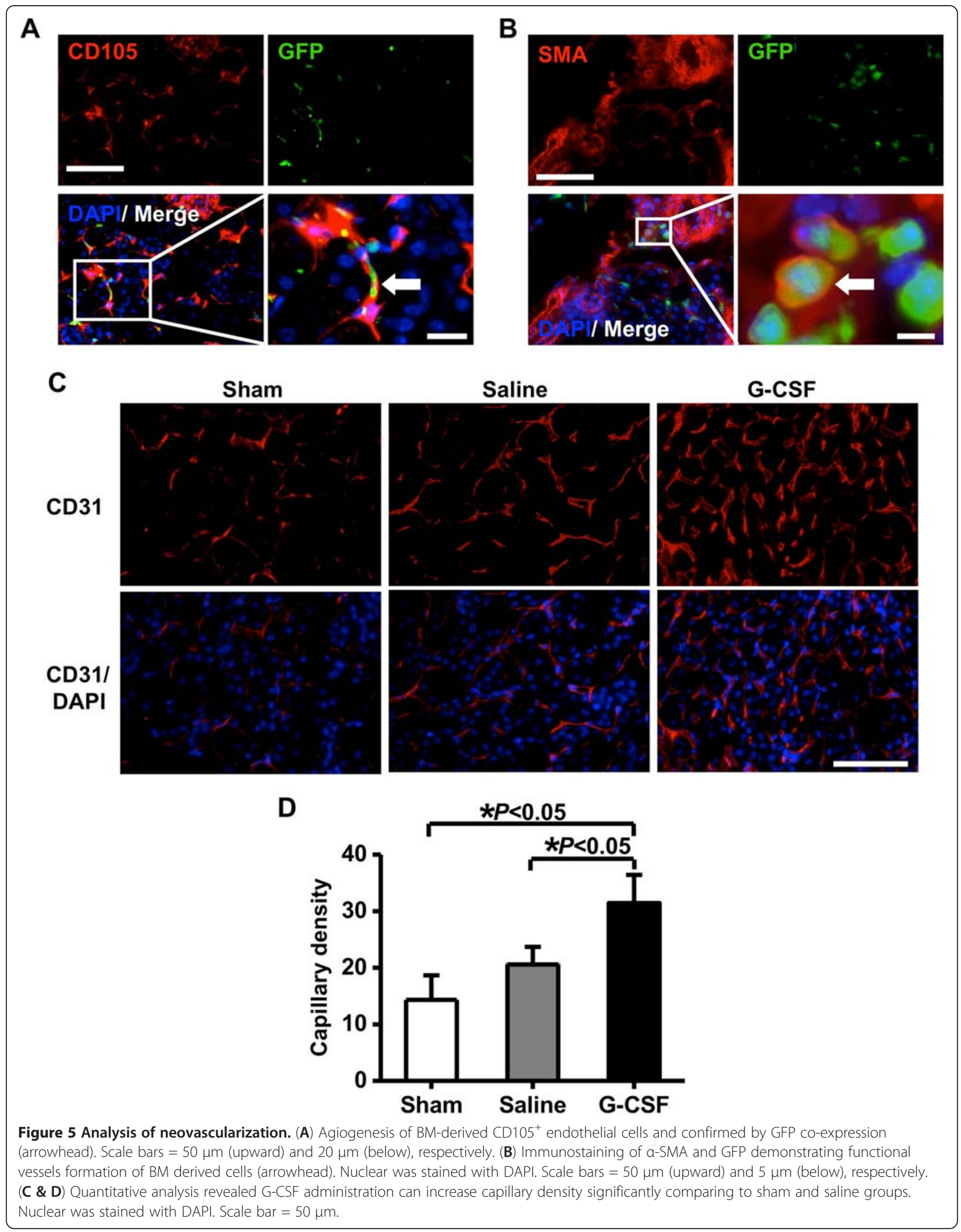




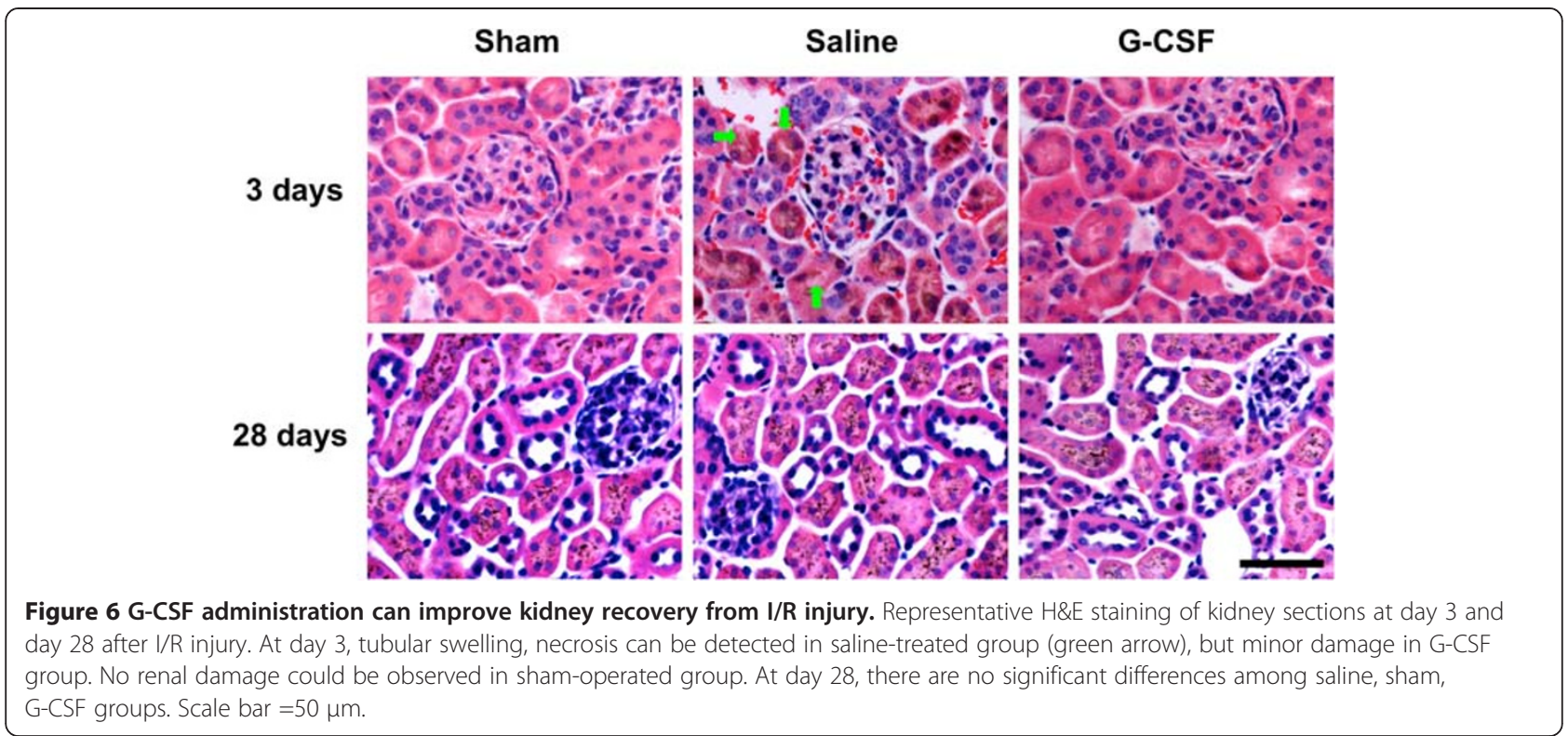

the kidney regeneration following AKI $[25,26]$. Thus blood-borne renal cells may be detected exclusively when the peripheral blood contains a large number of transplanted BM derived stem cells in long term. In this study, we set up BMT model other than bone marrow cells injection directly into kidney. The transplanted $\mathrm{GFP}^{+}$stem cells will migrate via the bloodstream throughout all experimental courses for several months, which would increase the possibility of BM derived stem cells residing in kidney and the usage of G-CSF would mobilize more HSCs into circulation. We confirmed that $\mathrm{BM}$ cells can integrate into damaged kidney. Moreover, we found for the first time that BM cells can differentiate into $\mathrm{Sca}-1^{+} / \mathrm{CD} 45^{-}$, or $\mathrm{c}-\mathrm{Kit}^{+} / \mathrm{CD} 45^{-}$renal stem cells over one to two months.

The efficiency of BM cell-based therapy to augment recovery from damaged tissues depends on not only efficient delivery of these cells to the desired target tissue, but also sufficient amount of stem cells. HSCs are unique in their ability to migrate to various sites, ensuring the safety and integrity of their regenerative potential. However, the number of traffic HSCs in blood stream is at an extremely low level. G-CSF has been used for the collection of BM cells used in allogeneic or syngeneic stem cell transplantation [27,28]. After G-CSF mobilization, the HSCs can release from their storage niche into circulation, ending their journey in the injured organs. We confirmed that G-CSF-treatment would mobilize BM stem cells from the bone marrow into ischemic kidneys and increase BM-derived renal stem cells after acute kidney ischemia, which perhaps is one of mechanisms of damaged kidney repair given by G-CSF. Previous reports showed that G-CSF stimulates angiogenesis in infracted kidneys, which acts to promote functional recovery of the damaged tissue $[2,28,29]$. These observations are based on the fact that HSCs mobilized by G-CSF can differentiate into vascular endothelial cells. A secondary finding in their studies, which was not explored further, was the beneficial effects of angiogenesis. Through increasing the vessel density, raising blood flow, G-CSF may enhance more BM-derived stem cells cycling and storing in the ischemic kidneys, and then the environment of injured kidneys may induce BM-derived cells incorporating into renal cells, getting the phenotypes of renal progenitors, differentiating into renal stem cells and terminal cells, finally participating in kidney functional repair. In addition, BM derived stem cells formed nested capillaries that might be helpful in supplying more oxygen and providing secondary protection of tubular cells [5]. Further studies are required to provide insight into the mechanisms.

\section{Conclusion}

In conclusion, the results of the present study confirmed that bone marrow derived stem cells could differentiate into renal stem cells. Furthermore, G-CSF enhanced recruitment of BM-derived renal progenitor cells and neovascularization in a murine AKI model to promote repair. The result of this study opens a new perspective for bone marrow therapy in kidney injury.

\section{Additional file}

Additional file 1: Figure S1. Immunohistochemical staining of GFP. Six months after I/R injury, consecutive sections of kidney were prepared and stained with GFP antibody or PBS (as control) and subsequently diaminobenzidine (DAB). GFP expression is observed in the glomeruli and interstitium. Arrows in (D) indicate the corresponding glomeruli in (A). 
Abbreviation: G, glomerulus; GFP, green fluorescent protein; $P$, renal pelvis; V, vessel. Original magnification: $\times 50($ A, D),$\times 100($ B, E), $\times 200($ C, F).

\section{Competing interests}

The authors declare that they have no competing interests.

\section{Authors' contributions}

$Z L, Y X$ and DK were the principal investigators and take primary responsibility for the paper. $Z L, D K, Y X, H L, X J, G F, Z H, Y X$ and $X X$ conceived and designed the experiments. $X X, G F, Y C, Q Z$, and ZL performed the experiments. XX participated in the statistical analysis. XJ, DK and ZL wrote the paper. All authors read and approved the final manuscript.

\section{Acknowledgement}

This work was partially supported by grants from National Key Scientific Program of China (2011CB964903), National Natural Science Foundation of China $(31071308,81172451,30970746,31260233,81220108015)$, Tianjin Natural Science Foundation of China (12JCZDJC24900), and Doctoral Fund of Ministry of Education of China (20090031110024)

\section{Author details}

'State Key Laboratory of Medicinal Chemical Biology, Key Laboratory of Bioactive Materials, Ministry of Education, Nankai University, Tianjin 300071, China. ${ }^{2}$ School of Medicine, Nankai University, Tianjin 300071, China. ${ }^{3}$ Department of Urology, Second Hospital of Tianjin Medical University, Tianjin Institute of Urology, Tianjin 300211, China. ${ }^{4}$ College of Basic Medicine, Yanbian University, Yanji, Jilin 133002, China. ${ }^{5}$ State Key Lab of Experimental Hematology, Institute of Hematology \& Hospital of Blood Diseases, Chinese Academy of Medical Sciences, Tianjin 300020, China.

Received: 12 January 2012 Accepted: 31 August 2012

Published: 10 September 2012

\section{References}

1. Pleniceanu O, Harari-Steinberg O, Dekel B: Concise review: Kidney stem/ progenitor cells: differentiate, sort out, or reprogram? Stem Cells 2010, 28:1649-1660

2. Bussolati B, Hauser PV, Carvalhosa R, Camussi G: Contribution of stem cells to kidney repair. Curr Stem Cell Res Ther 2009, 4:2-8.

3. Yeagy BA, Cherqui S: Kidney repair and stem cells: a complex and controversial process. Pediatr Nephrol 2011, 26:1427-1434.

4. Parikh CR, Lu JC, Coca SG, Devarajan P: Tubular proteinuria in acute kidney injury: a critical evaluation of current status and future promise. Ann Clin Biochem 2010, 47:301-312

5. Lee P-T, Lin H-H, Jiang S-T, Lu P-J, Chou K-J, Fang H-C, Chiou Y-Y, Tang M-J: Mouse Kidney Progenitor Cells Accelerate Renal Regeneration and Prolong Survival after Ischemic Injury. Stem Cells 2010, 28:573-584.

6. Bussolati B, Bruno S, Grange C, Buttiglieri S, Deregibus MC, Cantino D, Camussi G: Isolation of renal progenitor cells from adult human kidney. Am J Pathol 2005, 166:545-555.

7. Dekel B, Zangi L, Shezen E, Reich-Zeliger S, Eventov-Friedman S, Katchman $H$, Jacob-Hirsch J, Amariglio N, Rechavi G, Margalit R, Reisner Y: Isolation and characterization of nontubular sca-1 + lin- multipotent stem/progenitor cells from adult mouse kidney. J Am Soc Nephrol 2006, 17:3300-3314

8. Gupta S, Verfaillie C, Chmielewski D, Kren S, Eidman K, Connaire J, Heremans Y, Lund T, Blackstad M, Jiang Y, et al: Isolation and characterization of kidney-derived stem cells. J Am Soc Nephrol 2006, 17:3028-3040.

9. Lazzeri E, Crescioli C, Ronconi E, Mazzinghi B, Sagrinati C, Netti GS, Angelotti ML, Parente E, Ballerini L, Cosmi L, et al: Regenerative potential of embryonic renal multipotent progenitors in acute renal failure. J Am Soc Nephrol 2007, 18:3128-3138.

10. Kitamura S, Yamasaki Y, Kinomura M, Sugaya T, Sugiyama H, Maeshima $Y$, Makino H: Establishment and characterization of renal progenitor like cells from S3 segment of nephron in rat adult kidney. FASEB J 2005, 19:1789-1797.

11. Park HC, Yasuda K, Kuo MC, Ni J, Ratliff BB, Chander PN, Goligorsky MS: Renal Capsule as a Stem Cell Niche. Am J Physiol Renal Physiol 2010, 298:F1254-F1262.
12. Cheng Z, Ou L, Zhou X, Li F, Jia X, Zhang Y, Liu X, Li Y, Ward CA, Melo LG, Kong D: Targeted migration of mesenchymal stem cells modified with CXCR4 gene to infarcted myocardium improves cardiac performance. Mol Ther 2008, 16:571-579.

13. Qian H, Yang H, Xu W, Yan Y, Chen Q, Zhu W, Cao H, Yin Q, Zhou H, Mao F, Chen $Y$ : Bone marrow mesenchymal stem cells ameliorate rat acute renal failure by differentiation into renal tubular epithelial-like cells. Int J Mol Med 2008, 22:325-332.

14. Scadden DT: Circadian rhythms: stem cells traffic in time. Nature 2008, 452:416-417.

15. Lin F, Cordes K, Li L, Hood L, Couser WG, Shankland SJ, Igarashi P: Hematopoietic stem cells contribute to the regeneration of renal tubules after renal ischemia-reperfusion injury in mice. J Am Soc Nephrol 2003, 14:1188-1199.

16. Maeshima A, Sakurai H, Nigam SK: Adult Kidney Tubular Cell Population Showing Phenotypic Plasticity, Tubulogenic Capacity, and Integration Capability into Developing Kidney. J Am Soc Nephrol 2006, 17:188-198.

17. Kim K, Lee KM, Han DJ, Yu E, Cho YM: Adult stem cell-like tubular cells reside in the corticomedullary junction of the kidney. Int J Clin Exp Pathol 2008, 1:232-241.

18. Kale S, Karihaloo A, Clark PR, Kashgarian M, Krause DS, Cantley LG: Bone marrow stem cells contribute to repair of the ischemically injured renal tubule. J Clin Invest 2003, 112:42-49.

19. Lin F, Moran A, Igarashi P: Intrarenal cells, not bone marrow-derived cells, are the major source for regeneration in postischemic kidney. J Clin Invest 2005, 115:1756-1764.

20. Duffield JS, Park KM, Hsiao LL, et al: Restoration of tubular epithelial cells during repair of the postischemic kidney occurs independently of bone marrow-derived stem cells. J Clin Invest 2005, 115:1743-1755.

21. Szczypka MS, Westover AJ, Clouthier SG, Ferrara JL, Humes HD: Rare incorporation of bone marrow-derived cells into kidney after folic acid-induced injury. Stem Cells 2005, 23:44-54.

22. Masereeuw R: Contribution of bone marrow-derived cells in renal repair after acute kidney injury. Minerva Urol Nefrol 2009, 61:373-384.

23. Li B, Cohen A, Hudson TE, Motlagh D, Amrani DL, Duffield JS: Mobilized human hematopoietic stem/progenitor cells promote kidney repair after ischemia/reperfusion injury. Circulation 2010, 121:2211-2220.

24. Yeagy BA, Harrison F, Gubler MC, Koziol JA, Salomon DR, Cherqui S: Kidney preservation by bone marrow cell transplantation in hereditary nephropathy. Kidney Int 2011, 79:1198-1206.

25. Morigi M, Introna M, Imberti B, Corna D, Abbate M, Rota C, Rottoli D, Benigni A, Perico N, Zoja C, et al: Human bone marrow mesenchymal stem cells accelerate recovery of acute renal injury and prolong survival in mice. Stem Cells 2008, 26:2075-2082.

26. Togel F, Weiss K, Yang Y, Hu Z, Zhang P, Westenfelder C: Vasculotropic, paracrine actions of infused mesenchymal stem cells are important to the recovery from acute kidney injury. Am J Physiol Renal Physiol 2007, 292:F1626-F1635.

27. Yeoh JS, Ausema A, Wierenga P, de Haan G, van Os R: Mobilized peripheral blood stem cells provide rapid reconstitution but impaired long-term engraftment in a mouse model. Bone Marrow Transplant 2007, 39:401-409.

28. Tatsumi K, Otani H, Sato D, Enoki C, Iwasaka T, Imamura H, Taniuchi S, Kaneko K, Adachi Y, Ikehara S: Granulocyte-colony stimulating factor increases donor mesenchymal stem cells in bone marrow and their mobilization into peripheral circulation but does not repair dystrophic heart after bone marrow transplantation. Circ J 2008, 72:1351-1358.

29. Nafar M, Parvin M, Sadeghi P, Ghoraishian M, Soleimani M, Tabibi A, Nouralizadeh A, Amirkhanlou S, Barzi F, Alipour B: Effects of stem cells and granulocyte colony stimulating factor in reperfusion injury. Iran J Kidney Dis 2010, 4:207-213.

doi:10.1186/1471-2369-13-105

Cite this article as: Jia et al:: Bone marrow-derived cells can acquire renal stem cells properties and ameliorate ischemia-reperfusion induced acute renal injury. BMC Nephrology 2012 13:105. 